\title{
Contenidos digitales: aporte a la definición del concepto
}

\section{Resumen}

Este artículo procura contribuir a la discusión del tema de los contenidos digitales, los cuales conjugan diversos modos enunciativos, entre los que se cuentan imágenes, textos, sonidos o emoticones para configurar intenciones comunicativas, convirtiéndose en una herramienta aprovechada tanto por usuarios comunes como por organizaciones y marcas que buscan presencia en los medios digitales, especialmente en redes sociales virtuales. En la investigación que motivó este artículo: "Propuesta de implementación temática en creación de contenidos digitales para redes sociales. Caso programa de Diseño Visual de la Universidad de Caldas"1 se halló que a pesar de que hay suficiente información respecto de la estructura de los contenidos digitales, hace falta consolidar su definición, particularmente en áreas como la comunicación y el diseño, para llegar a acuerdos sobre su concepto y función comunicativa que sirva de aporte a estas disciplinas.

El rastreo bibliográfico de la investigación mostró que la noción de contenidos digitales, está en pleno desarrollo y es pertinente la reflexión teórica para ayudar a definir los alcances, así como el acotamiento de sus conceptos pensando en su apropiación para utilizarlos como instrumento de la actividad proyectual del diseño. Aportar a la definición del concepto de contenidos digitales apunta a facilitar los procesos de creación y permite comprender las dinámicas comunicacionales empresariales que se pueden generar en el denominado Social Media; aspecto este que favorecerá el actuar del diseñador, aportando con sus habilidades en un campo que al momento de la investigación ha estado marginado de las competencias con las que se forma a los diseñadores visuales de la Universidad de Caldas.

La investigación se realizó mediante un enfoque cualitativo reflexionando desde insumos teóricos de teorías del diseño y la comunicación; adicionalmente se realizaron e implementaron instrumentos bajo la técnica de entrevista cerrada a un grupo focal de estudiantes de Diseño Visual de la Universidad de Caldas. El trabajo empírico mostró que, a pesar de la popularización de los contenidos digitales, su acepción es imprecisa, lo cual tiene como consecuencia la limitación de sus potencias, su conceptualización, desarrollo y aplicación desde lo académico.
Margarita María Villegas

García

Magíster en Diseño y Creación

Interactiva

Profesora Universidad de Caldas.

Manizales, Colombia

Correo electrónico:

margarita.villegas@ucaldas.edu.co (ㄱ) orcid.org/0000-0001-5547-122X

\section{Google Scholar}

Walter Castañeda Marulanda

Doctor en Diseño y Creación Profesor Titular Universidad de Caldas. Manizales, Colombia Correo electrónico:

walter.castaneda@ucaldas.edu.co ๑ orcid.org/0000-0002-1466-0910 Google Scholar

Recibido: julio 12 de 2018 Aprobado: abril 02 de 2020

Palabras clave:

Community Manager, contenidos digitales, redes sociales, Social Media.

Proyecto desarrollado en la Maestría de Diseño y Creación Interactiva de la Universidad de Caldas y finalizado el año 2017. 


\section{Digital content: contribution to the definition of the concept}

\begin{abstract}
This article seeks to contribute to the discussion of the topic of digital content which combines several guidance modes including images, texts, sounds or emoticons to configure communicative intentions, becoming a tool used by both common users and organizations and brands that seek a presence in digital media, especially in virtual social networks. In the research that motivated this article called "Proposal of thematic implementation in creating digital content for social networks. Case: of Visual Design program at Universidad de Caldas"2, it was found that, despite the fact that there is enough information regarding the structure of digital content, it is necessary to consolidate its definition, particularly in areas such as communication and design to reach agreement on its concept and communicative function that serves as a contribution to these disciplines.
\end{abstract}

The documentary research showed that the notion of digital content is in full development and theoretical reflection is relevant to help define the scope, as well as the narrowing of its concepts thinking about their appropriation to use them as an instrument of the project activity of design. To contribute to the definition of the concept of digital content, aims at facilitating the processes of creation and allows understanding the business communication dynamics that can be generated in the so-called Social Media. This aspect will favor the acting of the designer contributing with their skills in a field which at the time of the research has been marginalized of competences with which visual designers at Universidad de Caldas are trained.

This research was conducted using a qualitative approach, reflecting from theoretical inputs of design and communication theories. In addition, instruments were made and implemented under the closed interview technique to a focus group of Visual design students from Universidad de Caldas. The empirical work showed that, despite the popularization of digital content, its meaning is imprecise which has as a consequence the limitation of its powers, its conceptualization, development and implementation from the academic point of view.

${ }^{2}$ This project was developed in the Master of Design and Interactive Creation of the Universidad de Caldas and completed in 2017.
Key words:

Community Manager, Digital

Content, Social Networks,

Social Media. 


\section{Introducción}

A partir de la popularización de redes sociales virtuales como Facebook, YouTube, Twitter, y posteriormente Instagram y Pinterest, se expandió también la utilización de terminales digitales para el consumo e intercambio de información, particularmente en Colombia, país en el que, entre los años 2000 al 2018 creció exponencialmente el consumo de contenidos digitales a través de redes móviles, Ilegando a contar actualmente, con más de 33 millones de usuarios. Como consecuencia de la popularidad alcanzada por las redes sociales, se volvió común que las personas de diferentes edades y estratos económicos generen e intercambien contenidos con fotografías, videos o artículos desde unas redes hacia otras dinamizando las maneras de comunicación interpersonal, ampliando los circuitos sociales y dispersando información; en otras palabras, estas dinámicas han posibilitado la construcción colectiva de comunicaciones alternativas basadas en un "caudal cultural común" (Sędek y Sląski, 2016, p. 115) que media en la comprensión de los significantes, entre quienes hacen uso de los contenidos.

La denominación de contenidos digitales, corresponde a un neologismo con el que se nombra a los mensajes multimodales transmitidos a través de las redes sociales virtuales y son el objeto principal del estudio presentado en este artículo. En la práctica del habla, la implementación del concepto puede atribuirse al uso conjuntivo de dos términos que involucran conceptos no correlacionados, pero cuyo sentido los ubica dentro de los entornos virtuales y en las acciones que ejerce cada concepto cuando se interactúa en la internet; es claro entonces que ambos términos guardan estrecha relación con el Social Media, teniendo en cuenta que bajo este término se cobijan los diferentes medios digitales como las páginas web, los blog, los podcast, las aplicaciones y también se suman las redes sociales virtuales. En consecuencia, los contenidos 
digitales se han de comprender como los componentes estructurales de los mensajes con carácter comunicativo que se divulgan en el Social Media.

Entonces, las redes sociales virtuales tienen una acepción transparente, debido al uso popularizado de redes de libre acceso, pero los contenidos no son una noción común entre los usuarios. No es atrevido mencionar que su definición se ha explorado poco en las disciplinas del diseño y la comunicación dejando abierta la discusión teórica. Dicha aseveración surge tras el trabajo de campo que consultó entre un número cercano a los treinta estudiantes quienes mostraron inexactitudes en lo que significa el término. No obstante, en la práctica cotidiana, las personas hacen uso de objetos, videos, sonidos, lenguaje e imágenes potenciando su postulación como recurso estructural de las nuevas formas de comunicación entre las empresas y sus usuarios, ya que este recurso ha marcado la diferencia al proveer interactividad, contacto inmediato y personalizado. Es por esta razón que se justifica la realización de estudios encaminados a revisar el marco teórico que podría darle sustento al término, para que los profesionales lo incorporen desde unas bases académicas que aporten en su formación. Por esta razón, el artículo se estructura en tres partes que abordan específicamente el tema de los contenidos digitales revisándolos desde las referencias bibliográficas, los investigadores que los han indagado en los recientes años, y aterrizando sus reflexiones al programa de Diseño Visual, de la Universidad de Caldas, describiendo los resultados de los instrumentos implementados.

\section{Método}

La investigación "Propuesta de implementación temática en creación de contenidos digitales para redes sociales. Caso programa de Diseño Visual de la Universidad de Caldas", se orientó desde la pregunta ¿Existe un concepto 
claro sobre lo que son los contenidos digitales? Su área problémica se extendió a las áreas implicadas en el desarrollo de los contenidos en medios digitales, puntualmente en redes sociales virtuales. Así que, en la indagación bibliográfica y dentro de los instrumentos aplicados, se tuvo en cuenta esta duda sobre la definición y comprensión de los contenidos digitales.

Como ya se había anunciado, dos áreas del conocimiento son las que facilitan la reflexión que busca contribuir y aproximar los contenidos digitales a una actividad proyectual encargada del diseño de comunicaciones visuales; en consecuencia, para satisfacer este propósito se tomaron teorías de la comunicación y del diseño para sugerir una mirada que considere los contenidos digitales como una modalidad en la que se estructuran mensajes cuyos sentidos han de ser pertinentes para los usuarios de redes sociales. Estos objetivos implican que los contenidos digitales sean observados a partir de su característica más importante y es que su complejidad está dada en su estructura multimodal. Debido a esta circunstancia, los contenidos digitales se exploran en este artículo como imágenes conformadas por componentes iconográficos, lingüísticos o sonoros, bien sea que se integren en una unidad o no; éstos tienen características diferentes a las imágenes que convencionalmente hacen parte del Diseño Visual. Por las anteriores razones el presente estudio complementa sus planteamientos a partir de aportes del periodismo, el diseño visual e industrial y la publicidad en redes sociales digitales, estableciendo conexiones que ayuden a comprenderlos, definirlos y entender los procesos que hay detrás de tal estructuración.

La investigación procuró llevar a la práctica las nociones exploradas desde las disciplinas mencionadas haciendo uso de la experiencia empírica y delimitando el estudio de manera espacial, social y conceptual. La delimitación espacial y social se refiere al hecho de haberse tenido en cuenta a la población estudiantil de Diseño Visual de la Universidad de Caldas, específicamente a los 
estudiantes de séptimo y noveno semestre. La delimitación conceptual se dio en el hecho de centrar el desarrollo de los instrumentos en el conocimiento, formación y discusión, en general, en torno a los contenidos digitales, el entendimiento del término y su pertinencia como tema académico. Así que se asumió un enfoque cualitativo para el desarrollo de esta investigación (Hernández-Sampieri, Fernández-Collado y Baptista, 2006), y mediante un instrumento de grupos focales se aplicaron instrumentos empíricos, de carácter práctico y argumentativo, con el fin de observar sus comportamientos y actitudes frente a la labor de creación de contenidos digitales, así como generar discusiones en torno al tema y a la pertinencia del mismo para su futuro laboral, evidenciándose que el término resultaba confuso. Los datos obtenidos con el instrumento de entrevista planteado por Hernández-Sampieri, Fernández-Collado y Baptista (2006), evidenciaron imprecisiones entre los estudiantes, no solo en la estructura, sino también en los modos que componen un contenido digital, apoyando las preguntas de la investigación y sugiriendo la necesidad de ahondar en su teorización, con el fin de convertirlos en una competencia del diseñador de cara a las nuevas alternativas de comunicación entre personas y empresas.

El trabajo empírico con los estudiantes del pregrado de Diseño Visual que cursaban séptimo y noveno semestre en la actividad académica Gestión del Diseño tomó una muestra homogénea y representativa que facilitó la obtención de datos. Con la modalidad de grupos de control y experimentales se propuso un enunciado a equipos de tres o cuatro estudiantes de los semestres mencionados, cuya propuesta buscaba la generación de contenidos digitales para un evento relacionado con el vigésimo quinto aniversario del programa académico. Debido al enfoque cualitativo de la investigación, el trabajo de campo se llevó a cabo en el ambiente natural de los estudiantes, que, para el caso de Diseño Visual, corresponde a las aulas laboratorio. 
Las redes sociales virtuales, como fenómeno de masas y como un espacio de interacción en la internet, les ofrecen a disciplinas como el diseño, oportunidades para desarrollar productos en varias de sus tipologías. Desde la academia, en el programa académico de Diseño Visual se plantean ejercicios que los estudiantes desarrollan en el aula mediante situaciones factibles de ser intervenidas desde la actividad proyectual, con problemas que pueden estar, o no, cercanos a la realidad de lo que pasa en el entorno laboral. Sin embargo, este tipo de contacto práctico no contempla la apropiación del término "contenidos digitales" como base para la comprensión y correcto desarrollo de éstos dentro de los medios digitales o Social Media y esto es lo que se procuró abordar como problema la investigación y es lo que se discute en este artículo. Las evidencias descritas, son razones para haber abordado un enfoque cualitativo con perspectiva interpretativa y, así mismo, para evidenciar el nivel de apropiación del tema indagando por discusiones en torno a la estructuración y desarrollo de contenidos digitales. A la vez, estos argumentos justifican la necesidad de comenzar a construir teoría alrededor de los contenidos digitales, viéndolos como un campo empírico en el que se están generando las bases que fortalecerán su conceptualización desde varias disciplinas sus procesos, métodos y argumentos.

\section{Discusión}

\section{Definición del lugar de estudio}

La imbricación que se suscita entre las redes sociales virtuales y los contenidos digitales se conjuga en un mensaje intencional como el de una empresa, este aspecto ha de analizarse en conjunto, si lo que se pretende es que su entendimiento sea redituable para la comunicación corporativa. Mientras las redes sociales han hecho parte de los intereses de la sociología, los contenidos digitales han sido estudiados por la ingeniería, pero al hacer 
mención de los contenidos digitales mediados por redes sociales digitales, su estudio se vuelve del interés de la comunicación y en este caso del diseño de comunicación visual. Sin embargo, para continuar explorando el potencial de efectividad comunicativa de los contenidos digitales, es necesario comprenderlos en el marco de su naturaleza visual, porque en esta modalidad adquieren la naturaleza de objetos dotados de sentido, por lo que su interpretación depende de dinámicas propias de la imagen, la cual acude a los estudios de la sicología de la percepción, la semiología y la comunicación; y, dado que el diseñador visual construye mensajes relevantes para una comunidad interesada, este aprovecha el peso que tienen las redes sociales virtuales para sus usuarios que, al final de cuentas, interactúan con los contenidos a través de las interfaces visuales.

Con este panorama, el primer paso fue la indagación bibliográfica en torno a los contenidos digitales hallando estudios en comunicación y ciencias humanas — como la sociología_ que proveen una mirada que entiende a los usuarios como productores y difusores de contenidos digitales. En tal sentido, son importantes los aportes de Lourdes Martínez Rodríguez, profesora en la Facultad de Comunicación de la Universidad de Murcia, dedicada a indagar sobre las acciones y desarrollos de los usuarios en torno a la generación de contenidos digitales cercanos a la comunicación periodística en medios digitales; investigación plasmada en varios artículos generados desde el año 2003 y que, para este documento en particular, su trabajo titulado La participación de los usuarios en los contenidos periodísticos de la red (2005) aporta el insumo requerido para la discusión y presenta una línea política similar a la que expone Manuel Castells quien analiza los aspectos inherentes a la democratización de la información en las redes sociales digitales.

Las relaciones de poder debidas a las dinámicas de socialización de la comunicación en redes han creado lo que Manuel Castells en Comunicación 
y Poder (2009) denomina la sociedad en red, para visualizar el contexto en el que ésta se da y cómo se puede considerar un terreno propicio para empoderar al pueblo y construir política mediante los contenidos digitales. Los análisis de Castells revisan las transformaciones sociales que derivan del uso de las redes observando en detalle conexiones espontáneas durante la Primavera Árabe y enunciando el potencial político conferido a los contenidos digitales que emergieron desde los usuarios.

Para este estudio fue importante conocer el ámbito político expuesto por Lourdes Martínez y por Castells, sin embargo, también es válido revisar la otra orilla de los contenidos, es decir, la línea de investigación que procura extraer beneficios del uso de contenidos en redes digitales, en la que se concibe el uso de recursos como el sonido, el video o la imagen para beneficios comunicacionales empresariales. En tal sentido el podcasting y la tipología audiovisual son entendidos como medios que permiten desarrollar contenidos digitales sonoros o visuales, no solo para captar audiencias, sino para divulgar información que fidelice y dé tratamiento particularizado a los usuarios; en este campo se aprecian los trabajos de Ignacio Gallego profesor de Periodismo y Comunicación de la Universidad Carlos III y Rafael Bigorra quien se dedica al desarrollo y periodismo de contenidos digitales para podcastings (2010).

Habiendo dejado claro que el estado del arte mostró los dos campos anteriores: el del interés por las dinámicas sociales de las redes y el del usufructo que brindan los contenidos digitales para beneficio de la empresa, se identificó un tercer campo de estudio y es el que saca partido de la información dejada por los usuarios en las redes, para conveniencia de los estudios socio demográficos o la identificación de tendencias e intereses. Los contextos mercadológicos han adquirido nuevas herramientas que permiten conocer de cerca lo que anhelan los usuarios destacando en este enfoque a Johana Cavalcanti y Juan Sobejano (2011). 
Es evidente, según surge de esta revisión, que tanto las redes como los contenidos se vienen observando desde sus repercusiones sociales, como herramientas de investigación de mercado o desde la utilidad que presentan para la comunicación empresarial. En un tiempo muy breve las agencias de diseño, los profesionales de la publicidad y las empresas comerciales han detectado las habilidades de sus clientes en el manejo de las redes sociales digitales y que su inmersión en una cultura digital les permite identificar con precisión los mensajes que circulan en los contenidos digitales a través de las redes que frecuentan.

No obstante, lo que se quiere mostrar en esta reflexión es que aún se requiere allanar caminos que le posibiliten al diseñador visual la utilización de los contenidos digitales, puesto que, en su competencia comunicativa, este profesional está capacitado para configurar los códigos con los que se dotan de sentido los mensajes. Debido a que en el pensum actual del programa académico de Diseño Visual no se integran estas tipologías de la imagen, se considera oportuno dar inicio a las discusiones sobre el tema con perspectiva a futuras reformas. Conviene entonces explorar algunas ideas mediante las que se estructure una concepción de los contenidos digitales para sugerir su integración a la actividad proyectual del Diseño Visual y así determinar el tipo de formación que debe tener el estudiante en el tema de contenidos digitales enfocados en las redes sociales virtuales.

\section{Contenidos Digitales: definirlos para comprenderlos}

Diversas actividades humanas que involucran herramientas conjugan conocimientos prácticos que resuelven necesidades naturales o artificiales, estas habilidades, al momento de replicarse, requieren de la reflexión para repetir los resultados exitosos o evitar fracasos; tales indagaciones sistematizan los procedimientos y delimitan las concepciones que se lograron a través de 
la práctica para tener certezas sobre ella. En las actividades prácticas a veces ocurren cruces entre distintas áreas y competencias con la finalidad de mejorar los procesos, pero no siempre en dichas prácticas se acude a la reflexión teórica como un horizonte que facilite el entendimiento de los alcances y métodos para su realización. Al traer esta reflexión al lugar de interés de este artículo, se hace evidente que los denominados contenidos digitales surgen como respuesta al cruce de escenarios y de necesidades materializadas en ellos, lo cual, es equivalente a decir que la internet ha creado los lugares para el intercambio de comunicaciones, mientras que los usuarios del común, tanto como los profesionales en comunicación, han dado origen a los contenidos. No obstante, y como se ha afirmado a partir del estado del arte, los contenidos digitales reclaman un cuerpo teórico que los delimite en su concepción, para que operen con mayor ajuste a las metodologías o las particularidades de las actividades que los usan en su praxis. De acuerdo con esta reflexión se deduce que para crear contenidos digitales es necesario debatir sobre lo que son y para qué se desarrollan. La postura que se expone en la presente reflexión postula que los contenidos digitales se presentan en varias tipologías de la comunicación visual (audiovisual, visual, sonoro y textual), siendo el Social Media uno de los que mayor usufructo obtienen con fines de comunicación; no obstante, no basta con producir contenidos diferentes, hace falta dar una mirada al término como tal, entendiendo la razón de ser de sus componentes para beneficio de la disciplina del diseño.

Un acercamiento superficial indica que un contenido es información codificada con fines comunicativos, es un mensaje para alguien, para una comunidad o población, por tanto, se ha de mostrar personal y directo, ya que involucra a la gente para presentarle algo que le interesa, entonces ha de buscar un tono personal e incluyente, como en una conversación que tienen dos entidades: el usuario y el mensaje o contenido digital. Si el contenido es mensaje, entonces su carácter comunicacional debe ser dirigido, claro y aportar a un tema de 
interés o suplir una necesidad en un grupo de personas. Se determina entonces que el contenido es información, porque pone a disposición de los usuarios conceptos e ideas del mundo en diversas maneras: en una imagen visual, auditiva, audiovisual o solo textual, con el fin de conectar a la gente con el mundo y actualizarla sobre lo que pasa en él.

Ahora viene el otro componente, lo digital, que remite a los entornos virtuales, a otras realidades creadas a partir de códigos binarios para generar espacios de encuentro e interacción que, para el caso de este estudio, ocurre entre usuarios, organizaciones y marcas. Lo digital, en términos comunicacionales, lleva a la posibilidad de acercarse más a lo que se percibía lejano, o sea, las distancias geográficas son superadas, y las oportunidades de intercambio de información con organizaciones y personas públicas son más evidentes.

Luego de definir y entender las partes que componen el término, se puede comenzar a construir una noción acotada de lo que es un contenido digital, partiendo de la comprensión de las dos variables que lo constituyen, es decir, el mensaje y el entorno en el que circula.

Respecto a la primera variable que es el mensaje, se entiende que es el objetivo del contenido que se digitaliza, infiriendo que al hacerlo se busca que su transmisión tenga carácter informativo. Pero, más que saber qué es lo que se va a decir, es necesario saber a quién se le va a decir, así el mensaje se estructura partiendo, en primera instancia, de una necesidad detectada en una audiencia, y en segundo momento, en el establecimiento de perfiles psicográficos dentro de esa audiencia; estos perfiles pueden definirse como aquellos rasgos detallados resultantes de la observación y análisis de estilos de vida, intereses, gustos, hábitos, valores, posturas políticas y sociales que comparten los miembros de una audiencia pretendida. 
En suma, el mensaje se configura también con la caracterización proveniente de algunos datos demográficos, que, de ser pertinentes, consideran el género, el estado civil, e inclusive la ubicación geográfica. Estos perfiles psicográficos también son determinantes en la decisión que se tome sobre la tipología o las tipologías que se abordarán para comunicar el contenido digital, estas tipologías son: textual, sonoro, audiovisual y visual, con el fin de impactar audiencias en entornos virtuales; pero para saber cómo estructurar el mensaje y definir la tipología más adecuada, se ha de tener en cuenta la concertación entre cliente y diseñador.

La segunda variable a considerar, el tiempo, se entiende como la noción de aquello que transcurre, pero ¿qué es lo que transcurre?, aunque rápidamente se puede deducir que se trata de una experiencia, seguiría siendo una respuesta somera y limitada a las posibilidades que proporciona el tiempo. En este marco, el del tiempo, se dan procesos complejos de percepción que involucran acciones encaminadas a comprender y asimilar el mensaje. El argentino Jorge Frascara lo expresa mejor cuando habla del dominio que de esta variable ha de tener quien proyecta un mensaje: "Percibir no es recibir información visual pasivamente. Percibir implica buscar, seleccionar, relacionar, organizar, establecer conexiones, recordar, identificar, jerarquizar, evaluar, aprender e interpretar" (2000, p. 62). En síntesis, muchas tareas se presentan al ejecutar un contenido digital y se pensaría que la duración es amplia para lo que ocurre al interior de los medios digitales, pero realmente varias de estas acciones son parte del ejercicio diario de una persona para comprender el mundo. Las acciones (relacionar, establecer conexiones) son funciones perceptuales y cognitivas que se dan con inmediatez en el acto de buscar referentes semánticos que no desliguen al sujeto de su realidad, en tanto que las categorizaciones (seleccionar, organizar, jerarquizar, evaluar) exponen el grado de relevancia que tiene la información presentada a través de estructuras sicológicas. 
Respecto a los referentes semánticos antes mencionados, se deduce que están ligados de manera directa al proceso de interpretación, pues allí es donde se pretende fortalecer la conexión con lo que se conoce del mundo y lo que se le presenta al usuario. Se hace referencia a la interpretación como proceso, porque requiere de recordación para el establecimiento de un nexo con algo o alguien para poder comprender, puesto que "Un mensaje connotado está construido en parte (...) por las experiencias individuales del receptor" (Frascara, 2000, p. 64).

Es entonces como la variable tiempo proporciona una atmósfera de búsqueda de valor de la información presentada, para encontrarle sentido al contenido digital y dotarlo de significado.

Ahora, respecto al contenido digital, este se publica, pero no quiere decir que la audiencia vaya a acceder a la información allí expresada en el momento mismo en que aparezca en la internet, aspecto que algunos investigadores como David Crystal denominan asincronía (2003, p. 8). El usuario accede en su tiempo, él es quien determina su relación con el contenido expuesto en el Social Media, esta relación es la experiencia que transforma el tiempo y la duración. Si bien los contenidos digitales tienen un tiempo de exposición determinado desde el acuerdo entre cliente y diseñador, este tiempo se condiciona por el del usuario. Tiempo de Exposición versus Tiempo del Usuario: el tiempo de exposición se definirá como el tiempo de publicación en el Social Media que tendrá el contenido digital, acordado e incluido en su proceso de desarrollo. Exponer el contenido digital es mostrarlo, ponerlo al alcance de la audiencia, es proponer para beneficiar y suplir una necesidad comunicativa, pero también es presentar una información relevante y pertinente que invite a la experiencia, a la interacción y cumplir con un objetivo trazado según su carácter. 
El tiempo del usuario es personal y tan subjetivo como el tiempo mismo, es íntimo y reflexivo lo que ocurre desde el simple hecho de compartir un mensaje de texto o entablar una conversación a través de las redes sociales a las que puede acceder desde su dispositivo: (...) los mensajes de texto parecen ser más relacionales, un mecanismo para mantener las conexiones sociales, más que algo informativo. Al mismo tiempo, los mensajes de texto también parecen ser usados para propósitos de planificación y estos mensajes pueden ser informativos. (Holtgraves y Korey, 2013, p. 294)

Lo relevante en este punto es hacer hincapié en el tiempo, la facilidad para comunicar un mensaje gracias a la inmediatez y al acceso a los dispositivos que permiten acceder a los medios digitales, propiciando el ambiente de intimidad para expresar sus pensamientos, pero también para comunicar algo que supone relevante para sus pares en las redes, por ejemplo. Así, el contenido digital que suscita, se expone con el objetivo de crear un impacto evidenciado en el efecto que causa en cada usuario que lo puede visualizar.

El usuario entonces, puede ver el contenido en su totalidad, interactuar con él, compartirlo con otros, comentarlo y generar así nuevos contenidos digitales en medio de las dinámicas sociales que en estos entornos virtuales se presentan.

Así que un contenido digital también es la manera de estructurar la información en una narrativa que se exprese a través de la imagen visual, la imagen auditiva, la imagen audiovisual y la imagen textual, con un mensaje claro y dirigido a una audiencia, y que es susceptible de compartirse en los diversos medios que componen el Social Media. Respecto al tiempo del usuario, es necesario aclarar esta variable que determina, en gran parte, la interactividad con los usuarios. Todo contenido que se publica en el Social Media se expone a ser visto en diferentes tiempos, puede ser en tiempo real, en un momento 
en el que los usuarios están accediendo al medio para generar interacción inmediata, o puede ser en el tiempo en que el usuario determine, en su propio tiempo, el cual, según la experiencia que esté teniendo, puede ser duradero o no. La experiencia que proporciona el contenido digital es un compendio de información y tiempo que depende de quién acceda a él y de su comprensión e interacción con el mensaje que comunica.

Como se viene mencionando, hablar de contenidos digitales es hablar de información depositada en el ciberespacio en varios formatos ${ }^{3}$ para ser leída, comprendida, transmitida y mutada; estas acciones son ejecutadas por usuarios del común, periodistas, marcas e influencers que son los usuarios influyentes dentro de una red social virtual, gracias al tipo de contenidos que crean y comparten entre sus seguidores, entre otros, a través de blog, páginas web y redes sociales, como los medios más comunes y populares en el mundo de la internet que hacen parte del Social Media.

\section{Desde el diseño visual ¿Qué hacer para que un contenido digital sea compartido?}

En primer lugar, son muchos los tipos de contenidos creados y muchas las características que poseen. Cada contenido lanzado al ciberespacio entra en el juego de la supervivencia interactiva ${ }^{4}$, que se refiere al hecho de sobresalir entre los de su mismo estilo con algo relevante y poderoso que llame la atención del usuario; básicamente, se debe sortear la contaminación de contenidos digitales para lograr el objetivo de ser compartido y, por qué no, viralizado ${ }^{5}$. Ahora bien,

\footnotetext{
${ }^{3}$ En este caso, el formato se refiere a la manera como se presenta el contenido digital, si es textual, solo audio, solo video o audiovisual; además, el formato también se refiere a cómo se adapta el contenido al tipo de plataforma, página web o tipo de red social en el que aparece.

${ }^{4}$ Cada información que se publica en Internet, ha de tener ciertas características que le permitan mantenerse vigente el mayor tiempo posible como: relevancia, ser tema de interés para un grupo de usuarios, innovación, aplicabilidad.

${ }^{5}$ Los contenidos virales son aquellos que son compartidos por un gran número de usuarios no solo en una red social, sino que muta de red en red logrando más impactos visuales y la posibilidad de ser nuevamente compartido. Viralización, entonces, es la acción de compartir a los contactos un contenido de interés general que se lleva a cabo en entornos virtuales, para el caso de este estudio, en redes sociales virtuales.
} 
para que un contenido digital cumpla el objetivo mencionado, debe contener información relevante para el público pretendido, esto es lo que persiguen los usuarios que diariamente navegan por redes y páginas, algo que los conecte, los informe $y$, sobre todo, algo que sea novedoso. Webear ${ }^{6}$ es un neologismo que se ha definido como el acto de navegar en la internet en busca de contenidos textuales o audiovisuales que impresionen por su estructura, por el tema que desarrollan y la manera como se presentan en medio de ese gran océano de información en donde los contenidos digitales buscan mantenerse a flote.

En cuanto a los tipos de contenidos, se mencionaron los textuales y los audiovisuales, también están los de solo audio, los contenidos de texto e imagen según la necesidad a suplir, pero conforme van desarrollándose este tipo de contenidos, van surgiendo plataformas que los soportan. Los medios o soportes se desarrollan para que los contenidos digitales se acomoden al tiempo del usuario y a entrar en interacción con él en tiempo real. El podcasting es una forma de captar un nuevo tipo de oyente que tiende a generarse su propio prime time debido a la falta de tiempo y a las facilidades que se le otorguen para escuchar lo quiere y cuando él quiere (Gallego y Bigorra, 2010 p. 309).

Desde el Diseño Visual, escuchar se trata de comprender la necesidad detectada y proporcionar una solución a ese problema. El acto de escuchar puede sugerir el hecho de captar la necesidad para dar una solución a ella, pero escuchar ha de entenderse como la detección de algo que hace falta mencionar o comunicar y que puede estar relacionado con características psicográficas que permitirán desarrollar contenidos digitales con los cuales los usuarios se sientan identificados y se apropien del mensaje en la experiencia personal que tengan.

\footnotetext{
${ }^{6}$ Pero más que un neologismo se puede tomar como verbo porque expresa una acción, en el caso de los hispanoparlantes, es una nueva palabra que tiene su origen en un extranjerismo: "web" y una terminación verbal en tiempo infinitivo; así que más que término o un objetivo, es un verbo híbrido que se pone en práctica cada vez que un usuario decide navegar en entornos virtuales.
} 
Los contenidos digitales se han ido adaptando no sólo al Social Media, sino a las características de los usuarios para los que van dirigidos, además, el usuario mismo no solo comparte y viraliza la información, también la crea. La participación de los usuarios como "creadores" de contenidos en la Internet abarca múltiples realidades que pueden ceñirse a un ámbito estrictamente interpersonal, o bien tener una vocación de "producción pública" con el fin de compartir ideas, opiniones, informaciones y conocimiento (MartínezRodríguez, 2005, p. 270). Los usuarios actúan ahora como creadores, o co-creadores cuando la creación de los contenidos digitales recae solo sobre los hombros de los comunicadores sociales, periodistas y, desde hace unos años, publicistas. Las audiencias evidencian su papel activo en los entornos virtuales y aportan contenidos de todo tipo que son compartidos por otros.

Los comunicadores sociales y periodistas, por sus competencias adquiridas desde la academia, son quienes tienen la capacidad de producir contenidos digitales retóricamente competentes. Los publicistas, con su capacidad para conceptualizar y concretar textos creativos, entraron en escena para buscar el impacto requerido y asegurar la eficiencia del contenido digital. Los influencers, con diversas profesiones, conocedores de un tema de interés específico, son autoridad para hablar, comentar y aportar, pero, ¿los diseñadores visuales? En el caso del Programa de Diseño Visual de la Universidad de Caldas, el estudiante se forma para que sistematice códigos visuales en mensajes, como se expresa en el objeto de estudio ${ }^{7}$. Esta competencia lo pone en el radar de los profesionales capacitados para crear contenidos digitales porque quiere decir que puede tomar los signos creados por la gente y aplicarlos a mensajes claros, comprensibles y dirigidos a ellos.

De otro lado, es cierto que los mensajes que generan los diseñadores visuales se basan en la retórica de la imagen; sin embargo, desde el punto de vista 
lingüístico, el mensaje visual se reduce a lo tipográfico, lo que quiere decir que en una tipología como la textual, el diseñador visual necesita retórica, capacidad de conceptualización de mensajes que se expresan en los términos de los usuarios. Incluyendo este componente lingüístico dentro de la propuesta de implementación temática que se pretende, se puede hablar con propiedad de los modos de comunicación y de los principios conceptuales que también son incluidos en el objeto de estudio del programa en mención.

\section{Conclusiones}

Es evidente que aún no se ha estructurado una definición fuerte en torno a lo que son los contenidos digitales, razón por la cual se presenta un acercamiento a la definición de lo que son, viéndolos como un aporte al tema en general, teniendo conocimiento de la evolución que han tenido los medios de comunicación y cómo se han instaurado en la internet escribiendo un nuevo capítulo en la historia de la comunicación. La pertinencia de un tema como los contenidos digitales dentro de la propuesta académica de un programa como diseño visual, se justifica desde la relación existente entre el mismo tema en discusión y el objeto de estudio de dicho programa, en cuanto al hecho de sistematizar códigos visuales en mensajes, teniendo en cuenta que, el proceso de creación de contenidos digitales involucra procesos del diseño visual con el mismo fin de comunicar a una audiencia determinada un mensaje conciso y comprensible. Así que, es necesario contar con una propuesta formativa clara que aporte a los estudiantes la manera de asumir la generación de contenidos digitales a través de un proceso para determinar el tipo de usuarios, sus necesidades y el plan para llevar a cabo la estructuración de dichos contenidos. 


\section{Referencias}

Castells, M. (2009). Comunicación y Poder. Madrid: Alianza.

Cavalcanti, J. y Sobejano, J. (2011). Social Media IOR las relaciones como moneda de rentabilidad. : Bubok Publishing S.L.

Frascara, J. (2000). Diseño Gráfico y Comunicación. Buenos Aires: Ediciones Infinito.

Gallego y Bigorra (2010). Podcasting. Nuevos modelos de distribución para contenidos sonoros. Barcelona: Advisory Board.

Hernández-Sampieri, R. Fernández-Collado C. y Baptista, L. P. (2006). Metodología de la Investigación. 4ta Ed. México: Editorial McGraw Hill.

Holtgraves, T. y Korey, P. (2013). Texting versus talking: An exploration in telecomunication languaje. Telematics and informatics, 30, 289-295. http://dx.doi.org/10.1016/j.tele.2013.01.002

Martínez-Rodríguez, L. (2005). La participación de los usuarios en los contenidos periodísticos de la red. En G. L. García (Coord.), El ecosistema digital: Modelos de comunicación, nuevos medios y público en Internet (p. 269-332). España: Universitat deValencia. https://docplayer.es/3074346La-participacion-de-los-usuarios-en-los-contenidos-periodisticos-de-lared.html

Sędek, M. y Sląski, U. (2016). Explorando la combinación de lenguaje e imagen: el caso de la metáfora multimodal. Itinerarios, 22, 113-128. http://itinerarios. uw.edu.pl/wp-content/uploads/2016/06/Sedek-Magdalena_Explorando-lacombinacion-de-lenguaje-e-imagen_el-caso-de-la-metafora-multimodal.pdf

Como citar: Villegas-García, M. M. y Castañeda-Marulanda, W. (2020). Contenidos digitales: aporte a la definición del concepto. Revista KEPES, 17(22), 257-276. https://doi.org/10.17151/kepes.2020.17.22.10 